\title{
Expansão do capital e suas relações na formação docente
}

The expansion of capital and its relationships in teaching education

La expansión de capital y sus relaciones en la enseñanza de la educación 


\title{
Resumo
}

Este estudo aborda a formação do professor, com o objetivo de refletir sobre a educação e a tecnologia na sociedade contemporânea, tendo como base o método do materialismo histórico-dialético. Como resultado percebemos que a área educacional está passando por reformas neoliberais a partir dos anos de 1990 na América Latina. Essas reformas estão sob a direção empresarial, transmitindo valores que legitimam os interesses dominantes e mantêm as relações de exploração e expropriação da classe trabalhadora. Concluímos que a Base Nacional Comum Curricular (BNCC), a reforma do Ensino Médio, o ensino remoto e as medidas de cortes do investimento público em saúde e educação são indícios do descaso com a qualidade da formação das classes trabalhadoras. E que a tecnologia se transformou em instrumento de submissão da força de trabalho a um tempo sem limite, levando a humanidade à exaustão.

Palavras-chave: Educação. Formação de professores. Capitalismo

\begin{abstract}
This study addresses teacher education, with the aim of reflecting on education and technology in contemporary society, based on the method of historical-dialectical materialism. As a result, we realize that the educational area is undergoing neoliberal reforms since the 1990s in Latin America. These reforms are under business direction, transmitting values that legitimize dominant interests and maintain working class exploitation and expropriation relations. We conclude that the Common National Curriculum Base (BNCC), the reform of secondary education, remote education and the measures to cut public investment in health and education are signs of the disregard for the quality of training of the working classes. And that technology has become an instrument for submitting the workforce to an unlimited time, leading humanity to exhaustion.
\end{abstract}

Keywords: Education. Teacher training. Capitalism

1 Professora de Artes Visuais da Universidade Federal do Maranhão, Campus São Bernardo. Doutora em Artes Visuais pela Universidade do Estado de Santa Catarina. Lattes: http://lattes.cnpq.br/9856652011091771. ORCID: https://orcid.org/0000-0002-0448-6824. E-mail: janine.perini@ufma.br. 


\section{Resumen}

Este estudio aborda la formación del profesorado, con el objetivo de reflexionar sobre la educación y la tecnología en la sociedad contemporánea, a partir del método del materialismo histórico-dialéctico. Como resultado, nos damos cuenta de que el área educativa está experimentando reformas neoliberales desde la década de 1990 en América Latina. Estas reformas están bajo la dirección empresarial, transmitiendo valores que legitiman los intereses dominantes y mantienen las relaciones de explotación y expropiación de la clase trabajadora. Concluimos que la Base Curricular $\mathrm{Na}$ cional Común (BNCC), la reforma de la educación secundaria, educación a distancia y las medidas para recortar la inversión pública en salud y educación son signos del desprecio por la calidad de la formación de las clases trabajadoras. Y esa tecnología se ha convertido en un instrumento para someter a la fuerza laboral a un tiempo ilimitado, llevando a la humanidad al agotamiento.

Palabras clave: Educación. Formación de profesores. Capitalismo 
Este artigo aborda a formação do professor de uma forma ampla e contextualiza, refletindo sobre a educação e a tecnologia na sociedade contemporânea, tendo como base o método do materialismo histórico-dialético. Este método é uma concepção formulada por Marx no século XIX. Assim, essa pesquisa não parte daquilo que os homens dizem, imaginam e pensam, mas sim, dos próprios homens, de seus processos de vida, da realidade vivida.

Precisamos conhecer a sociedade atual para problematizar a formação de docentes, considerando as contradições da sociedade. Netto (2011) aborda que a sociabilidade é o resultado "[...] do trabalho, que constituirá o modelo da práxis ${ }^{2}$ - é o processo, movimento que se dinamiza por contradições, cuja superação o conduz a patamares de crescente complexidade, nos quais novas contradições impulsionam as outras superações" (NETTO, 2011, p. 31). Esse modelo da práxis, é a relação entre teoria e prática, "[...] prática, na medida em que a teoria, como guia da ação, molda a atividade do homem, particularmente a atividade revolucionária; teórica, na medida em que esta relação é consciente" (VÁZQUEZ, 2007, p. 109). Dessa maneira, o movimento que se dinamiza por contradições é o processo de transformação da realidade.

A atividade humana está em processo, em movimento e em contradições 3 . "A contradição sempre expressa uma relação de conflito ${ }^{4}$ no devir do real. Essa relação se dá na definição de um elemento pelo que ele não é. Assim, cada coisa exige a existência do seu contrário, como determinante e negação do outro" (CURY, 2000, p. 30). Nessa relação de conflitos, o artigo tem como eixo a "contradição", uma categoria escolhida entre "[...] a riqueza categorial da obra marxiana - resultado do caráter também específico do método dialético de Marx e da sua fundamentação ontológico-materialista" (NETTO, 2015, p. 09). O autor aponta que essa categoria tem como base a riqueza do acervo cultural e científico do qual Marx se apropriou criticamente.

Para abordar a formação de professores, precisamos compreender a sociedade na qual os docentes estão inseridos e conhecer o seu contexto econômico, político, social, cultural e educacional. Fundamentalmente, compreender como esse modelo de formação foi forjado e a que interesses ele serve. Para fazer essa análise, começamos com uma reflexão sobre a globalização e a ideologia neoliberal no Bra-

2 "A expressão práxis refere-se, em geral, a ação, a atividade, e, no sentido que lhe atribui Marx, à atividade livre, universal, criativa e auto criativa, por meio da qual o homem cria (faz, produz), e transforma (conforma) seu mundo humano e histórico e a si mesmo; atividade específica ao homem, que o torna basicamente diferente de todos os outros seres. Nesse sentido, o homem pode ser considerado um ser da práxis, entendida a expressão como o conceito central do marxismo, e este como a "filosofia" (ou melhor, o "pensamento") da "práxis". A palavra é de origem grega e, de acordo com Lobkowicz, "refere-se a quase todos os tipos de atividade que o homem livre tem possibilidade de realizar; em particular, a todos os tipos de empreendimentos e de atividades políticas" (1967, p.9). Do grego, a palavra passou ao latim e, deste, às línguas europeias modernas" (BOTTOMORE, 2012, p. 460).

3 "Embora o conceito possa ser usado como uma metáfora para qualquer espécie de dissonância, divergência, oposição ou tensão, ele assume um significado particular no caso da ação humana (ou, mais geralmente, de qualquer ação orientada para um objetivo), em que especifica qualquer situação que permita a satisfação de um fim unicamente às expensas de um outro, isto é, uma conexão ou coerção" (BOTTOMORE, 2012, p. 135).

4 Conflito para Marx está ligado as classes sociais, para ele é o resultado direto da divisão social pelo poder e riqueza. 
sil, com Shiroma e Santos (2014), Fonseca da Silva (2016), Duarte (2008), entre outros autores. Em seguida, apresentamos considerações sobre a expansão do capital com o teórico István Mészáros, que traz uma visão marxista, com um princípio histórico sobre a atualidade. Mészáros $(2002 ; 2010 ; 2015)$ faz uma crítica ao capital e realiza reflexões sobre a sociabilidade contemporânea e a lógica que a preside. Depois, escrevemos, embasados em Saviani e Galvão (2021), sobre a educação em tempos de pandemia, onde a tecnologia ganhou forças no cenário nacional. Pretendemos, assim, situar a formação de professores no cenário da atualidade, evidenciando as contradições presentes na sociedade.

\section{A sociedade atual e a ideologia neoliberal nas políticas educacionais}

Para refletir sobre a formação inicial dos professores é necessário analisar a realidade para além dos fenômenos aparentes (KOSIK, 1976). Entender como se dá a reforma do Estado brasileiro, por que ela sofre influência internacional e por que a área educacional é um espaço de disputas entre interesses de classes contrárias.

No Brasil, a globalização e a ideologia neoliberal são propostas atuais e influenciam diretamente na área econômica, política, social, cultural e educacional do país. A implementação das políticas neoliberais começou no Brasil a partir de 1990, com o Governo Collor, porém, de 1995 a 2002, com o Governo Fernando Henrique Cardoso (FHC), a reforma se consolidou. Mais tarde, mesmo com a entrada da esquerda no poder, com Luiz Inácio da Silva (2003-2010) e Dilma Roussef (2011-2016), as ações neoliberais continuaram e aprofundaram-se com o impeachment da presidente Dilma, no governo de Michel Temer e, na atualidade, vivemos as consequências do governo Bolsonaro. Shiroma e Santos (2014) apresentam que:

Nas últimas duas décadas do século XX, reformas de cariz neoliberal instituídas
nos países submetidos aos ajustes econômicos foram caracterizadas por me-
didas de austeridade que subtraíram dos trabalhadores vários direitos sociais
duramente conquistados ao longo da história (SHIROMA; SANTOS, 2014, p. 21).

Os autores pontuam que um aspecto das reformas neoliberais está centrado na regressão dos direitos sociais. No decorrer do artigo, eles apresentam outros pontos a serem refletidos, como a privatização da educação; a participação da comunidade na escola, pautada no voluntariado e na cooperação; a autonomia da escola voltada ao isolamento e à descentralização, que retira do Estado a responsabilidade pelo financiamento da educação pública e o foco da educação na formação de um cidadão que acompanhe as mudanças do capitalismo. Para Marx, o Estado "[...] não é mais do que a organização da classe explorada para garantir a sua exploração e manter na submissão os explorados" (MARX, 2013, p. 20). Para o autor, a burguesia é que dirige o Estado e regula os interesses do capital. 
"A educação em seu sentido geral, não apenas escolar, possui compromissos inexoráveis com o sistema capitalista e que a tarefa da escola tem sido a de legitimá-lo, difundi-lo e consolidá-lo" (SHIROMA; EVANGELISTA, 2014, p. 13). A educação, vista aqui, como atividade mediadora ${ }^{5}$ no seio da prática social global, cria, nesse sentido geral, as condições necessárias para os sujeitos sociais aderirem ao capitalismo. As reformas e políticas promovidas pelo Estado auxiliam nesse processo de conformação docente. Para as autoras, a escola muitas vezes deixa de apresentar o conhecimento historicamente produzido para desenvolver uma aprendizagem voltada a hábitos e valores, despolitizando os sujeitos, tornando-os cidadãos flexíveis, produtivos, competitivos, conformados para enfrentar as incertezas do dia-a-dia e suportar as crises do capitalismo.

Mészáros (2015) coloca que essas crises, social e política, são geradas estruturalmente e são visíveis mundialmente. Observando os acontecimentos sociais, econômicos e políticos do século XX, Mészáros (2010), afirmou que a crise do capital é estrutural, com quatro aspectos principais: com caráter universal, alcance global, escala de tempo permanente e modo de desdobrar rastejante com sua complexa maquinaria. $O$ autor lembra que quando não se pode mais esconder as manifestações da crise, os ideólogos do capital, que antes possuíam a solução final para todos os problemas sociais, agora conferem a tal crise fatores puramente tecnológicos, criando para isso novas ideologias como "Segunda Revolução Industrial", "Colapso do trabalho", "Revolução da informação" e "Descontentamentos culturais da sociedade pós-industrial".

Essas novas ideologias também aparecem na área educacional. Mari (2014) afirma que o slogan "sociedade do conhecimento" surge nas políticas oficiais dos últimos vinte anos (LDB, Lei de Inovação Tecnológica, ProUni, REUNI) ${ }^{7}$ com a finalidade de construir um discurso educacional para a privatização e o consenso social. Para o autor, essas ideias defendem a aproximação entre universidade e empresa, conhecimento e informação, conhecimento técnico e educação como investimento estratégico e fator de produção.

5 Cury (2000) afirma que a educação é mediação, porque filtra uma maneira de ver as relações sociais. Ela é organizadora e transmissora de ideias.

6 Sociedade do conhecimento é um termo utilizado como alternativa para o termo sociedade da informação. Surgiu em 1973, com o estadunidense Daniel Bell em seu livro O advento da sociedade pós-industrial. Neste livro, ele formula que o eixo principal desta sociedade será o conhecimento teórico e adverte que os serviços baseados no conhecimento terão de se converter na estrutura central da nova economia e de uma sociedade sustentada na informação, onde as ideologias serão supérfluas. Esta expressão reaparece com força nos anos 90 , no contexto do desenvolvimento da Internet e das TIC. A partir de 1995, foi incluída na agenda das reuniões dos chefes de Estado, em fóruns da Comunidade Europeia e dos Estados Unidos, assim como pelo Banco Mundial. A partir de 1998, foi escolhida, primeiro na União Internacional de Telecomunicações e, depois, na ONU para nome da Cúpula Mundial programada para 2003 e 2005. Disponível em: https://vecam.org/archives/article519.html. Acesso em: 15 abr. de 2021.

7 Lei de Diretrizes e Bases da Educação Nacional (LDB), n. 9394/1996 (BRASIL, 1996); Lei de Inovação Tecnológica, n. 10.973/2004 (BRASIL, 2004); Programa Universidade para todos (ProUni), Lei no11.096 (BRASIL, 2005); Programa de Apoio a Planos de Reestruturação e Expansão das Universidades Federais (REUNI), Decreto n. 6.096/2007 (BRASIL, 2007). 
Duarte (2008) faz uma crítica ao termo "sociedade do conhecimento". Para ele: "A assim chamada sociedade do conhecimento é uma ideologia produzida pelo capitalismo, é um fenômeno no campo da reprodução ideológica do capitalismo" (DUARTE, 2008, p. 13). Para o autor, as ilusões da sociedade do conhecimento cumprem funções ideológicas na sociedade capitalista contemporânea. Ele aponta cinco ilusões: o conhecimento nunca esteve tão acessível; a habilidade de mobilizar conhecimento é muito mais importante que a aquisição de conhecimentos; o conhecimento é uma convenção cultural; os conhecimentos têm todos o mesmo valor; e o apelo à consciência dos indivíduos supera os grandes problemas da humanidade. Apresentando essas ilusões da sociedade do conhecimento, ele nos lembra:

Quando uma ilusão desempenha um papel na reprodução ideológica de uma sociedade, ela não deve ser tratada como algo inofensivo ou de pouca importância por aqueles que busquem a superação dessa sociedade. Ao contrário, é preciso compreender qual o papel desempenhado por uma ilusão na reprodução ideológica de uma formação societária específica, pois isso nos ajudará a criarmos formas de intervenção coletiva e organizada na lógica objetiva dessa formação societária (DUARTE, 2008, p. 13-14).

Para o autor, a crença na sociedade do conhecimento enfraquece as críticas radicais ao capitalismo, esmaecendo a luta por uma revolução e ficando o sujeito focado apenas nas questões mais atuais. Duarte (2008) aponta que o termo sociedade do conhecimento está associado às pedagogias do aprender a aprender, que segundo o autor são as pedagogias pelas competências, o construtivismo, a escola nova e o aprender fazendo da pedagogia de John Dewey, que fundamentam a atual Base Nacional Comum Curricular - BNCC. Nessas pedagogias, o aluno aprende sozinho e isso se situa em um nível mais elevado do que a aprendizagem resultante da transmissão ${ }^{8}$ de conhecimentos pelo professor. Assim, é mais importante adquirir o método científico do que o conhecimento científico já existente. Nessas escolas, a atividade do aluno deve ser impulsionada e dirigida pelos interesses e necessidades da própria criança e a educação deve preparar os indivíduos para acompanharem a sociedade em acelerado processo de mudança. Essas escolas são fundamentadas no biólogo Piaget (1896-1980), que compreendia o indivíduo como um sujeito pronto, bastando à escola o papel de facilitar o processo de externalização do conhecimento. Dessa maneira, para algumas pedagogias a escola deixa de ser um espaço da apropriação do conhecimento e passa a ser um lugar para adaptar o conhecimento já existente para uma sociedade capitalista. As pedagogias ativas esvaziam a escola de formação e desqualificam o professor como intelectual, bastando uma formação

8 Duarte entende que é "[...] possível postular uma educação que fomente a autonomia intelectual e moral por meio da transmissão das formas mais elevadas e desenvolvidas do conhecimento socialmente existente" (DUARTE, 2008, p. 08). 
instrucional dirigida à prática. Uma educação voltada à adaptação ao trabalho, adequando o aluno à sociedade regida pelo capital e seus interesses exploratórios.

Nessa sociedade capitalista burguesa, o trabalho ${ }^{9}$ define-se por sua característica alienante, pois conforme Behring e Boschetti (2011), "[...] o trabalho perde seu sentido como processo de humanização, sendo incorporado como atividade natural de produção para a troca, independente de seu contexto histórico" (BEHRING; BOSCHETTI, 2011, p. 50). Nessa perspectiva, a força de trabalho é tratada como mercadoria, possuindo duplo caráter, sendo produtora de valor de uso e de valor de troca ${ }^{10}$ e a quantidade do trabalho é o que vai determinar a grandeza do valor. Para entender melhor a lógica do capital, Harvey explica:

O capital é um processo, e não uma coisa. É um processo de reprodução da vida social por meio da produção de mercadorias em que todas as pessoas do mundo capitalista avançado estão profundamente implicadas. Suas regras internalizadas de operação são concebidas de maneira a garantir que ele seja um modo dinâmico e revolucionário de organização social que transforma incansável e incessante a sociedade em que está inserido. O processo mascara e fetichiza, alcança crescimento mediante a destruição criativa, cria novos desejos e necessidades, explora a capacidade do trabalho e do desejo humano, transforma espaços e acelera o ritmo da vida. Ele gera problemas de superacumulação para os quais há apenas um número limitado de soluções possíveis (HARVEY, 2009, p. 307).

Esse processo de natureza capitalista, que o autor explica acima, se reproduz na vida social e cria novas necessidades para as pessoas consumir. E se intensifica com as tecnologias, fazendo com que o descarte sistemático aconteça a partir da ilusão de que o novo é melhor. Esse processo possui suas etapas, para Mészáros (2010), o capital possui três dimensões fundamentais: a produção, o consumo e a circulação, podendo essa última também ser intitulada como distribuição ou realização. Para o autor, a natureza do capital está em superar suas barreiras. Assim, os limites da produção são superados com a expansão do consumo e vice-versa. Consequentemente, os limites parecem meramente barreiras a serem transcendidas. Para o autor, essas três dimensões têm seus limites absolutos e o modo como o capital lida com as contradições é intensificando-as, transferindo-as para um nível mais elevado ou exportando-as para um país diferente. A crise do capital é do pró-

9 O trabalho, para Marx (2013), é uma condição especificamente humana. É uma atividade intrínseca ao ser humano. É o processo no qual o ser humano atua sobre a natureza modificando-a e, ao mesmo tempo, se modifica.

10 Para Marx, valor é a forma social e histórica da riqueza da época mercantil. Ele só existe se as relações forem mercantis. Assim, o valor de troca é a forma de manifestação do valor. O valor de troca é relativo, pois depende de outra mercadoria. Também, é variável, porque varia em tempo e espaço. Conceito retirado da aula ministrada pelo Prof. Reinaldo A. Carcanholo sobre o livro O capital, de Marx. Disponível em: https://youtu.be/Sk11gl6xwmg. Acesso em: 19 jul. 2021 
prio capital, de sua natureza. Ela é necessária para a expansão do capital, para que continue superando suas barreiras.

A superação da crise recai em toda a sociedade, alastrando-se também na área educacional. "Um intenso processo de propaganda forjou um senso comum sobre a necessidade de reformas do Estado e educacionais para superação das crises" (SHIROMA; SANTOS, 2014, p. 22). Os autores colocam que as propagandas inserem o Estado como não eficiente e lento, promovendo o individualismo e induzindo o indivíduo a não esperar por ações do poder público e sim deles próprios e da iniciativa privada. Um exemplo disso tem sido as exaustivas campanhas de desqualificação de professores e de servidores públicos no governo Bolsonaro. Os autores ainda afirmam que "[...] a crise do capital foi interpretada como uma crise fiscal de ineficiência da gestão e dos serviços públicos. Para superá-la, os reformadores brasileiros utilizaram estratégias e princípios muito próximos aos adotados na reforma do Estado britânico [...]" (SHIROMA; SANTOS, 2014, p. 23-24).

Os autores defendem que o Estado Britânico influenciou o Brasil com suas críticas negativas à burocracia do Estado. Mais adiante, no texto, eles colocam que também influenciou pela proposta de administração pública voltada aos resultados, dando ênfase à profissionalização do servidor público, ofertando salários por desempenho, flexibilizando os contratos de trabalho em detrimento da estabilidade, descentralizando os serviços públicos e fazendo parcerias entre o Estado e a sociedade civil, dando origem ao setor "público não estatal".

Percebe-se que a crise do capital não está confinada apenas à esfera socioeconômica, mas também às instituições políticas, atingindo a área cultural, artística, social, educacional e, assim, a sociedade em geral. Mészáros (2010) apresenta a contradição do sistema de dominação, com milhões de excluídos e famintos passando fome, com trilhões de alimentos desperdiçados. Barreto (2012) mostra que as práticas pedagógicas associadas às Tecnologias da Informação e Comunicação (TIC) aprofundam a divisão entre possuidores e despossuídos. Também Fonseca da Silva (2016) alerta que a globalização beneficia apenas uma parcela da população mundial, ampliando a desigualdade. A autora afirma que a globalização se expandiu pela exploração capitalista, que a cultura se tornou um grande negócio e que as tecnologias deram suporte para a mudança do processo de manufatura para o de industrialização.

Dentro do capital, a tecnologia é uma prática produtiva paradoxalmente auto-orientada. Mészáros (2002), explica:

Paradoxal no sentido de que é tanto autônoma (à medida que é liberada pelo capital dos constrangimentos imediatos das necessidades humanas, e, desse modo, capacitada a perseguir, até certo ponto, sua própria linha de desenvolvimento), como servilmente subordinada aos ditames orientados para o lucro da lógica imanente do capital. Como resultado, a tecnologia pode avançar na realização de seus objetivos autoimpostos, independentemente das implicações negativas de tal orientação autônoma, tanto em relação à 
taxa de utilização decrescente - manifestada, por um lado, na superprodução em massa de mercadorias e, por outro, no excesso acumulado de capacidade produtiva - como em relação ao seu impacto sobre o trabalho vivo (MÉSZÁROS, 2002, p. 666).

Percebe-se, por Mészáros, que a tecnologia serve as necessidades humanas, mas também serve o capital. O capital só funciona pelas suas contradições e que a tecnologia não fica fora disso. Ele continua seu pensamento:

Controles e limitações só podem ser trazidos à cena post festum, depois do dano infligido. Ao mesmo tempo, os corretivos viáveis dentro dos limites do capitalismo são bastante limitados, já que o impacto negativo da autonomia tecnológica - que, em situações de crise, parece contradizer os interesses vitais do sistema - está de fato completamente afinado com os ditames materiais do capital, inalteradamente orientados-para-o-lucro, mesmo que, do ponto de vista do capital, seja preferivel manter ocultas as contradições subjacentes (MÉSZÁROS, 2002, p. 666).

O autor coloca que os seres humanos e a tecnologia são necessários para o capital e ao mesmo tempo supérfluos. Qualquer coisa que não possa ser mantida dentro dos limites fixados pela busca de lucros deve ser reprimida. O desenvolvimento da tecnologia não está ligado às necessidades humanas e sim às necessidades da produção, visando sempre à expansão do capital.

$\mathrm{Na}$ arte, as tecnologias e a publicidade também aparecem. A TV, por exemplo, está ligada a necessidade humana de buscar conhecimento e de se estar informado, mas ela existe muito mais pela necessidade da produção e da publicidade. A publicidade de mercadorias, a troca ou acúmulo cada vez mais rápido de aparelhos pelos consumidores, fazem com que o capital se expande.

O artista sul-coreano, nascido em Seul, Nam June Paik (1932-2006), criou durante os Jogos Olímpicos de Seul, uma torre enorme feita inteiramente de monitores retransmitindo as olimpíadas a partir do sinal de dez países diferentes (Irlanda, Israel, Brasil, Áustria, Japão, Corea do Sul, Estados Unidos, China, União Soviética e Alemanha), como podemos observar na Figura 1. 


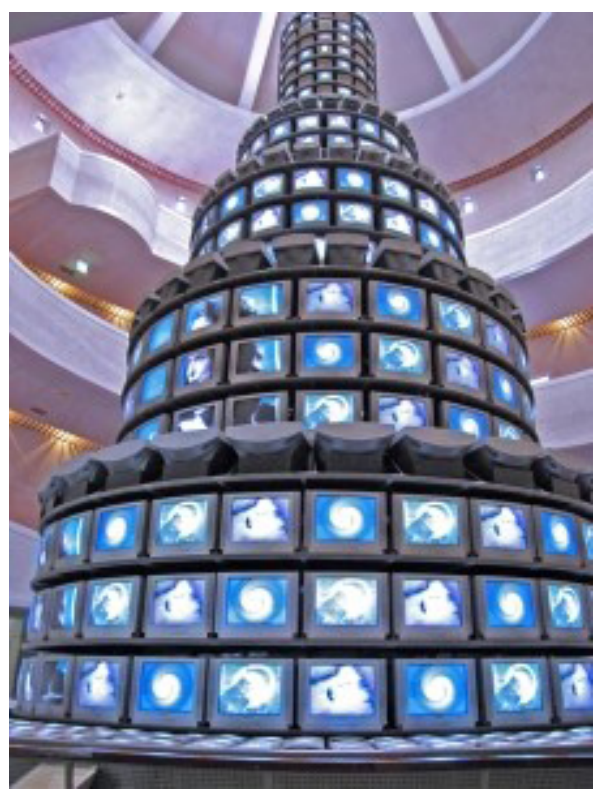

Figura 1. Nam June Paik. The More The Better (Quanto mais, melhor). Instalação.1988.

Fonte: https://comunicacaoeartes20122.wordpress.com/2013/02/18/nam-june-paik-ao-longo-da-vida-e-carreira/

O artista, constrói uma torre em forma piramidal a partir da imagem e do movimento, unindo nessa obra a cultura pop e a cultura de massa na repetição da imagem. Essa obra reflete sobre como a televisão possui capacidade de atrair pessoas de várias regiões geográficas e contextos sociais diferentes através da experiência compartilhada. Quem sabe ele a fez tão alta, em forma de torre, para alcançar o céu, nos lembrando da Torre de Babel ${ }^{11}$, nos alertando aos cuidados que temos que ter com as tecnologias.

Jameson (1996) escreve que a tecnologia da sociedade contemporânea é hipnótica e fascinante.

[...] a tecnologia pode servir como uma forma abreviada para designar o poder do propriamente humano e portanto antinatural presente no trabalho humano descartado acumulado em nossas máquinas - um poder alienado, o que Sartre chama de a contrafinalidade do prático-inerte, que se volta contra nós em formas irreconhecíveis e parece constituir-se no horizonte distópico massivo de nossa práxis coletiva e individual (JAMESON, 1996, p. 61).

\footnotetext{
11 Torre de Babel: "Segundo o Antigo Testamento (Gênesis 11,1-9), torre construída na Babilônia pelos descendentes de Noé, com a intenção de eternizar seus nomes. A decisão era fazê-la tão alta que alcançasse o céu. Esta soberba provocou a ira de Deus que, para castigá-los, confundiu-lhes as línguas e os espalhou por toda a Terra. Este mito é, provavelmente, inspirado na torre do templo de Marduk, nome cuja forma em hebraico é Babel ou Bavel e significa "porta de Deus". Hoje, entende-se esta história como uma tentativa dos povos antigos de explicarem a diversidade de idiomas". Disponível em: https://www.historiadomundo.com.br/babilonia/torre-babel.htm.
} 
Observamos pela citação de Jameson, a contradição existente na tecnologia. Ela serve ao ser humano, mas também o deixa alienado. Para o autor, a tecnologia é um poder alienante. Outro exemplo dessa alienação, "[...] a lógica do simulacro, com sua transformação de novas realidades em imagens de televisão, faz muito mais do que meramente replicar a lógica do capitalismo tardio: ela a reforça e a intensifica" (JAMESON, 1996, p. 72). O ser humano fica alienado pelo consumismo, por meio das imagens da televisão, outdoors, revistas, jornais, pelo rádio e por todas as vias da publicidade. $O$ autor acredita que o capitalismo é a melhor e a pior coisa que aconteceu à humanidade e a esfera autônoma da cultura explodiu por todo o domínio social. Para o autor, a cultura se expandiu a ponto que tudo pode ser considerado cultural.

Refletindo sobre o pensamento de Jameson (1996), também se pode afirmar que a tecnologia é a melhor e a pior coisa que aconteceu à humanidade. Fonseca da Silva (2016) assegura que as tecnologias aumentam a produção na lógica do capitalismo, proporcionando conforto em nossas vidas e também explorando nosso tempo livre. A autora problematiza a tecnologia como relação social. Na educação, a entrada das novas tecnologias corrobora a exploração dos trabalhadores como foi nas fábricas. A autora afirma igualmente que a inserção destas tecnologias na escola faz a educação retornar às correntes pedagógicas tecnicistas, mas com nova roupagem. Encontramos professores desqualificados pela perda da formação intelectual em detrimento à formação técnica e aligeirada. Quando acontece essa desqualificação dos profissionais da educação, muitas vezes entra nas políticas públicas com o slogan "educação de qualidade", com auxílio de tecnologias da informação e comunicação, "[...] os reformadores tentam esvaziar o sentido político do ensino e abordá-lo como uma questão meramente técnica" (SHIROMA; SANTOS, 2014, p. 36). Para os autores, a educação deixa de educar para a cidadania, formando pessoas não críticas para fazer parte da ação social alienadora. Jameson (1996), apresentou essa alienação, pela tecnologia e pela publicidade. Dessa maneira, a alienação é uma forma que o capitalismo tem para seu sucesso, pois quanto mais pessoas alienadas, mais consumidores teremos.

\section{Tecnologia: impactos na docência atual}

O mundo está vivendo em pandemia, desde 2020, por conta do COVID-19. Nesse cenário, a tecnologia ganhou forças dentro da educação. Por conta do necessário isolamento social, as escolas não puderam continuar com suas atividades presenciais e adotaram o ensino remoto. Saviani e Galvão (2021) abordam as múltiplas determinações desse ensino, para eles: os interesses privatistas são colocados na educação como mercadoria; a exclusão tecnológica da maioria da população brasileira excluiu milhares de alunos das escolas; houve uma ausência de democracia nos processos decisórios para adoção do modelo remoto e se intensificou a precarização e intensificação do trabalho para docentes e demais servidores das instituições. 
Para os autores, houve um discurso sinalizando que a adesão pelo ensino remoto era por falta de alternativa, mas para eles, foi uma escolha política.

Nesse cenário, percebemos que a falta de políticas públicas voltadas para a educação nesse período gerou um déficit incalculável na educação do país. Milhares de estudantes não têm acesso ao ambiente virtual de qualidade, com equipamentos adequados, bom acesso à internet e familiarizados com as tecnologias, e isso, fez com que a evasão tenha aumentado muito dentro das escolas. Os docentes, também, tiveram prejuízos com o ensino remoto, pois arcaram com os custos de energia, internet, equipamentos tecnológicos e formação no uso pedagógico de ferramentas virtuais. Além, de terem que adaptar o espaço físico de suas casas, conciliando a vida familiar com a profissional. Dessa forma, muitos tiveram sua saúde física e mental abaladas por conta da intensificação e precarização do trabalho.

Saviani e Galvão (2021) alertam que o ensino remoto aprofundou o “[...] processo de conversão da educação em mercadoria, na esteira da privatização que implica sempre a busca da redução dos custos, visando ao aumento dos lucros" (SAVIANI; GALVÃO, 2021, p. 39). Para os autores, o ensino remoto é uma alavanca aos serviços dos interesses mercadológicos e a tecnologia que era desde a origem do ser humano a extensão de seus braços para facilitar seu trabalho, diminuindo as horas de trabalho diário e aumentando o tempo disponível para o lazer, o cultivo do espírito e das formas estéticas, hoje é, um "[...] instrumento de submissão da força de trabalho a um tempo sem limite, conduzindo o ser humano à exaustão" (SAVIANI; GALVÃO, 2021, p. 39).

Atualmente, esse cansaço físico e emocional é muito frequente aos docentes que estão trabalhando no ensino remoto, pois a maioria utiliza o Whatsapp para se comunicar com seus alunos, fazendo grupos para mandar material, tirar dúvidas e para manter um diálogo com pais e alunos. Dessa forma, recebem mensagens sete dias por semana, a qualquer hora do dia ou da noite. 


\section{Considerações}

A área educacional está passando por reformas, com vistas a ampliar o modelo neoliberal implantado a partir dos anos de 1990 na América Latina. Nesse cenário inicial surgiu um projeto pedagógico sob a direção empresarial, que transmite os valores que legitimam os interesses dominantes e mantêm as relações de exploração e expropriação da classe trabalhadora. Já na atualidade, as estratégias são mais amplas e complexas. As medidas, que aparentam terem sido implementadas de forma rápida, na verdade vêm ao longo dos anos sendo inseridas em conta-gotas. A desqualificação da escola, do professor, dos conteúdos e das correntes pedagógicas liberais criou um cenário propício para a entrada das tecnologias na escola como redentora dos problemas educacionais.

Atendendo aos interesses do Capital, o gasto de dinheiro público com assessorias, materiais e projetos da iniciativa privada, inclusive a modalidade de formação à distância, corroboram o enfraquecimento da escola pública. A Base Nacional Comum Curricular (BNCC), a reforma do Ensino Médio, o ensino remoto sem uma estrutura adequada e as medidas de cortes do investimento público em saúde e educação são indícios do descaso com a qualidade da formação das classes trabalhadoras. 


\section{Referências}

BEHRING, Elaine. BOSCHETTI, Ivanete. Capitalismo, liberalismo e origens da política social. In: BEHRING, Elaine. BOSCHETTI, Ivanete. Política Social: Fundamentos e história. 9 ed. São Paulo: Cortez, p. 82-111, 2011.

BOTTOMORE, Tom (org.). Dicionário do pensamento Marxista. Rio de Janeiro: Editora Jorge Zahar, 2ed., 2012. Disponível em: https://edisciplinas.usp.br/ pluginfile.php/2543654/mod_resource/content/2/Bottomore_dicion\%C3\%A1rio_ pensamento_marxista.pdf. Acesso em 07 jul. de 2021.

BRASIL. Decreto no. 6.096, de 24 de abril de 2007. Institui o Programa de Apoio a Planos de Reestruturação e Expansão das Universidades Federais - REUNI. Brasília, CN, 2007. Disponível em: http://www.planalto.gov.br/ccivil_03/_Ato20072010/2007/Decreto/D6096.htm. Acesso em: 27 mar. 2021.

Lei de Inovação Tecnológica. Lei n. 10.973, de 2 de dezembro de 2004. Dispõe sobre incentivos à inovação e à pesquisa científica e tecnológica no ambiente produtivo e dá outras providências, Brasília, DF, 3 dez., 2004. Disponível em: http://www.planalto.gov.br/ccivil_03/_ato2004-2006/2004/lei//10.973.htm. Acesso em: 27 mar. 2021.

Ministério da Educação e do Desporto. Lei no 9.394, de 20 de dezembro de 1996. Lei de Diretrizes e Bases da Educação Nacional. Diário Oficial da República Federativa do Brasil, Brasília, DF, 1996. Disponível em: http://www.planalto.gov.br/ ccivil_03/leis/L9394.htm. Acesso em 27 jul. de 2021.

Programa Universidade para todos (ProUni). Lei no 11.096, de 13 de janeiro de 2005. Institui o Programa Universidade para Todos - PROUNI, regula a atuação de entidades beneficentes de assistência social no ensino superior; altera a Lei no 10.891, de 9 de julho de 2004, e dá outras providências. Brasília: DF, 2005. Disponível em: http://www.planalto.gov.br/ccivil_03/_Ato2004-2006/2005/Lei/ L11096.htm. Acesso em: 27 mar. 2021.

BARRETO, Raquel Goulart. A recontextualização das tecnologias da informação e da comunicação na formação e no trabalho docente. In: Dossiê: "A cultura digital e a formação de professores: uma questão em debate". Revista: Educação \& Sociedade. vol.33, n 121, Campinas, out./dez. 2012. 
CURY, Carlos Roberto Jamil. Educação e contradição: elementos metodológicos para uma teoria crítica do fenômeno educativo. São Paulo: Cortez: Autores Associados, 2000.

DUARTE, Newton. Sociedade do conhecimento ou sociedade das ilusões? Campinas, SP: Autores Associados, 2008.

FONSECA da SILVA. Maria Cristina da Rosa. Fundamentos sócio-históricos para a compreensão da formação em artes: impactos das tecnologias digitais. In: FONSECA da SILVA, M. C. R (org.). Formação, arte e tecnologias: Contribuições do campo sócio-histórico. Florianópolis, 2016.

HARVEY, David. Condição Pós-Moderna. São Paulo: Edições Loyola, 18ำed., 2009.

JAMESON, Fredric. Pós-modernismo. A lógica cultural do capitalismo tardio. São Paulo. Ed. Ática. 1996.

KOSIK, Karel. Dialética do Concreto. Tradução de Célia Neves e Alderico Toríbio. $2^{a}$ ed., Rio de Janeiro: Paz e Terra, 1976.

MARI, Cezar Luiz de. Algumas questões relativas à proposição sociedade do conhecimento. In: EVANGELISTA, Olinda (org.). O que revelam os slogans na política educacional. Araraquara, SP: Junqueira \&Marin, 2014.

MARX, Karl. O capital. Tradução e condensação de Gabriel Deville. Bauru, SP: EDIPRO, 3. ed., 2. reimp. 2013.

MÉSZÁROS, István. A taxa de utilização decrescente e o significado de "tempo disponível". In: MÉSZÁROS, István. Para além do capital: rumo a uma teoria de transição. São Paulo: Boitempo, p.650-674, 2002.

Boitempo Editorial, 2015.

A Montanha que Devemos Conquistar. São Paulo: . Das crises cíclicas à crise estrutural. In: A atualidade

histórica da ofensiva socialista. São Paulo: Boitempo, p. 69-98, 2010.

NETTO, José Paulo. Introdução ao estudo do método de Marx. São Paulo: Expressão Popular, 2011. 
SAVIANI, Dermeval; GALVÃO, Ana Carolina. Educação na pandemia: a falácia do ensino remoto. In: Universidade e Sociedade ANDES-SN, ano XXXI, janeiro, 2021. Disponível em: https://www.andes.org.br/img/ midias/0e74d85d3ea4a065b283db72641d4ada_1609774477.pdf Acesso em: 09 nov. 2021.

SHIROMA, Eneida Oto; EVANGELISTA, Olinda. Apresentação. In: EVANGELISTA, Olinda (org.). O que revelam os slogans na política educacional. Araraquara, SP: Junqueira \&Marin, 2014.

SHIROMA, Eneida Oto; SANTOS, Fabiano Antonio dos. Slogans para a construção do consentimento ativo. In: EVANGELISTA, Olinda (org.). O que revelam os slogans na política educacional. Araraquara, SP: Junqueira \&Marin, 2014.

VÁZQUEZ, Adolfo Sánchez. Filosofia da práxis. São Paulo: Expressão Popular, 2007.

Submetido em $26 / 07 / 2021$

Aprovado em 06/11/2021 